\title{
Percepção e levantamento sobre a educação AMBIENTAL DOS ALUNOS DA EDUCAÇÃo BÁSICA DE UMA ESCOLA MUNICIPAL DE CUIABÁ/MT
}

\author{
PERCEPTION AND SURVEY ON ENVIRONMENTAL EDUCATION OF STUDENTS \\ OF BASIC EDUCACION IN A MUNICIPAL SCHOOL OF CUIABÁ/MT
}

DOI: http://dx.doi.org/10.23926/

\section{Jaqueline Costa de Souza Raupp \\ Graduação em Engenharia \\ Florestal pela Universidade \\ Federal de Mato Grosso \\ (UFMT) \\ Graduação em Tecnologia \\ em Gestão Ambiental pelo \\ Instituto Federal de \\ Educação, Ciência e \\ Tecnologia de Mato Grosso \\ (IFMT) \\ rauppjaqueline@gmail.com}

\section{Josane do Nascimento Ferreira Cunha}

Doutoranda REAMEC pela

Universidade Federal de

Mato Grosso (UFMT)

Professora do Instituto

Federal de Educação,

Ciência e Tecnologia de

Mato Grosso (IFMT)

josane.cunha@blv.ifmt.edu.b
Resumo: Nas últimas décadas, o aumento da produção de lixo urbano fez com que o acúmulo deste atingisse a capacidade máxima dos aterros sanitários, gerando problemas sociais. Assim, há a necessidade de encontrar um destino ambientalmente adequado para estes materiais, e a reciclagem é uma das melhores soluções para resolver o problema de acúmulo de resíduos sólidos. O estudo realizado com alunos de uma escola municipal em Cuiabá/MT, teve por objetivo analisar a percepção ambiental em relação à Educação Ambiental e Prática dos 3'Rs (Reduzir, Reutilizar, Reciclar). A abordagem metodológica ocorreu por meio de palestra, oficina voltada à temática, orientações sobre os 3R's e avaliação da percepção ambiental dos alunos através da aplicação de questionários, além da proposição a separação dos resíduos sólidos em casa. Nos resultados foi possível verificar a percepção como um todo, acerca do que os alunos entendem sobre os temas ligados ao meio ambiente, sua importância e a necessidade de sua proteção. Espera-se que estes discentes levem a experiência que tiveram em sala de aula, para dentro de suas casas, influenciando nos hábitos familiares e até mesmo da vizinhança, disseminando assim, os conhecimentos adquiridos.

Palavras-chave: Ensino básico; Resíduos sólidos urbanos; Reciclagem e reutilização de materiais.

\begin{abstract}
In the last decades, the increase in the production of urban waste caused its accumulation reaching the maximum capacity of the sanitary landfills, generating social problems. Thus, there is the need to find an environmentally appropriate destination for these materials, and recycling is one of the best solutions to the problem of solid waste accumulation. The study carried out with students of a municipal school in Cuiabá / MT, aimed to analyze the environmental perception towards the Environmental Education and the Practice of 3'Rs (Reduce, Reuse, Recycle). The methodological approach was based on a lecture, a workshop focused on the theme, guidance on 3R's and evaluation of the students' environmental perception through the application of questionnaires, in addition to proposing the separation of solid wastes at home. In the results it was possible to verify the perception as a whole, about what the students understand about the themes related to the environment, its importance and the need for its protection. It is hoped that these students will take the experience they had in the classroom, into their homes, influencing the habits of the family and even the neighborhood, thus disseminating the knowledge acquired.

Keywords: Basic education; Urban solid waste; Recycling and reuse of materials.
\end{abstract}




\section{INTRODUÇÃO}

A partir da segunda metade do século XX, a crescente importância com os problemas ambientais e preocupação da população em relação à racionalidade do uso dos recursos naturais, renováveis ou não, influenciou diretamente a atividade econômica, levando a debates direcionados à relevância do estudo da sustentabilidade. Nas últimas décadas, o aumento da produção de resíduos sólidos urbano (RSU) fez com que o seu acúmulo atingisse a capacidade máxima dos aterros sanitários, gerando problemas sociais. Assim, há a necessidade de encontrar um destino ambientalmente adequado para esses materiais.

Como grande parte do resíduo produzido pode ser utilizado como insumo para a criação de novos produtos, surgiu o conceito de reciclagem, uma das melhores soluções para o problema de acúmulo de resíduos sólidos que vem crescendo mundo afora, considerando que a população está sensibilizando-se e tendo mais consciência no que diz respeito à reciclagem e reutilização de materiais.

O desenvolvimento sustentável está diretamente ligado a economia, pois reciclando, economiza-se matéria-prima e barateia-se o processo de fabricação de novos produtos, consequentemente preservando a natureza com a redução da poluição. De tal modo, a reciclagem e reutilização de materiais, resulta em redução do resíduo, economia de matériaprima extraída da natureza, redução da poluição, geração de novos empregos, conscientização sobre a questão ambiental e estímulo do trabalho participativo.

O artigo 225 da Constituição da República Federativa do Brasil de 1988 atribui a todos os brasileiros, até as futuras gerações, direitos e deveres para com o meio ambiente. Considerando isso, a Educação Ambiental (EA) é um tema que deve ser amplamente abordado nas escolas de ensino básico, a fim de garantir a preservação do meio ambiente para as futuras gerações.

O estudo da percepção e levantamento sobre a educação ambiental foi realizada com alunos do $5^{\circ}$ Ano Matutino da Escola Municipal de Ensino Básico Padre Raimundo Conceição Pombo Moreira da Cruz em Cuiabá/MT, com o objetivo de analisar e levantar dados sobre a percepção ambiental destes em relação à Educação Ambiental e Prática dos 3'Rs (Reduzir, Reutilizar, Reciclar).

Especificamente realizou-se uma palestra e uma oficina voltada à prática da $\mathrm{EA}$, além de promover orientações sobre os 3R's; avaliar a percepção ambiental dos alunos por meio da aplicação de questionários; e a partir disso, propor a separação dos resíduos sólidos em casa. Com isso, espera-se que a introdução da EA na escola, por meio da realização de palestra e 
oficina sobre reciclagem e reutilização de materiais, possa despertar nos alunos a consciência de preservação e conservação do meio ambiente, contribuindo para a formação de cidadãos responsáveis e preocupados com as questões ambientais, tornando-os agentes multiplicadores de bons hábitos.

\section{REFERENCIAL TEÓRICO}

A conferência de Estocolmo em 1972 foi o primeiro evento mundial sobre questões ambientais envolvendo homem e meio ambiente, surgindo então a proposta de educação ambiental (EA) (DIAS, 2004). Seguido pelo Encontro Internacional em Educação Ambiental realizado em Belgrado em 1975, que resultou na Carta de Belgrado, a qual determinou metas, objetivos, público alvo, e as diretrizes básicas para os programas de EA (BONACORSO, 2009). E conforme Dias (2004), em 1977 na cidade de Tbilisi, iniciou a primeira conferência internacional de EA, de onde saíram as definições, objetivos e princípios para a EA.

Com participação de 170 países, a RIO-92, como ficou conhecida a Conferência das Nações Unidas sobre o Meio Ambiente e Desenvolvimento, ocorreu no ano de 1992 na cidade do Rio de Janeiro-RJ, que segundo Souza (2014) consagrou o conceito de desenvolvimento sustentável e contribuiu para a conscientização de que os danos ao meio ambiente não era apenas responsabilidade dos países menos desenvolvidos. Assim como, elaborou a Agenda 21, um Plano de Ação para o Século XXI, deixando clara a necessidade de adotar medidas em âmbito nacional e internacional, quanto à proteção ambiental (DIAS, 2004).

Em 1999 foi instituída a Política Nacional de Educação Ambiental (PNEA), Lei nº.795, de 27 de abril de 1999:

Art. $1^{\circ}$ Entende-se por educação ambiental os processos por meio dos quais o indivíduo e a coletividade constroem valores sociais, conhecimentos, habilidades, atitudes e competências voltadas para a conservação do meio ambiente, bem de uso comum do povo, essencial para à sadia qualidade de vida e sua sustentabilidade.

Para Bonacorso (2009) a EA busca conscientizar e sensibilizar a todos a respeito da preservação ambiental, uma vez que a conservação do Meio Ambiente é importante para a manutenção da vida, para promoção de possibilidades de desenvolvimento e para formação de cidadãos responsáveis e conscientes. Em conformidade com isso, Medeiros (2012), diz que a educação ambiental não é somente um ramo da educação formal, deve tratar dos problemas relacionados à sociedade, propondo mudanças, trazendo assim, melhoria para todos. Na escola, a EA serve como instrumento utilizado para sensibilização, buscando construir um meio 
ambiente sadio, formar cidadãos atuantes e conscientes da importância da preservação ambiental, vivenciando a realidade do meio onde estão inseridos.

A educação ambiental na escola é hoje o instrumento muito eficaz para se conseguir criar e aplicar formas sustentáveis de interação sociedade-natureza. Este é o caminho para que cada indivíduo mude de hábitos e assuma novas atitudes que levem à diminuição da degradação ambiental, promovam a melhoria da qualidade de vida e reduzam a pressão sobre os recursos ambientais (SANTOS, 2007, p. 45).

No trabalho desenvolvido por Laranja (2016, p. 27) com alunos do $5^{\circ}$ ao $9^{\circ}$ ano de uma escola estadual em MT, constatou-se que:

A percepção ambiental utilizada como possibilidade pedagógica, pode ser uma alternativa importante para a educação ambiental, contribuindo para a mudança de percepção dos alunos sobre o lugar onde vivem, destacando o valor da natureza e ligando os saberes que eles já têm consigo com o saber escolar.

Considerando a Política Nacional dos Resíduos Sólidos (PNRS), instituída pela Lei $\mathrm{n}^{\circ} 12.305$, de 02 de agosto de 2010, que conforme inciso VIII do Art. $6^{\circ}$ tem como princípio: “O reconhecimento do resíduo sólido reutilizável e reciclável como um bem econômico e de valor social, gerador de trabalho e renda e promotor de cidadania".

Sabemos que o aumento do consumo eleva, consequentemente, o resíduo gerado pela sociedade, fazendo com que a capacidade dos aterros sanitários ultrapasse seus limites. $\mathrm{Na}$ verdade, muitas cidades brasileiras não possuem um local adequado para a destinação correta dos Resíduos, sendo, portanto, descartados em Lixões a céu aberto, causando não somente problemas sociais, mas principalmente ambientais e à saúde humana.

Marckwski (2006) relata a importância do desenvolvimento de atividades voltadas ao Reaproveitamento-Reciclagem-Reuso dos resíduos com o intuito de diminuir a produção do lixo, e logo, a poluição causada pela disposição e destinação incorreta. Assim sendo, a redução do consumo está diretamente associada à diminuição da produção de resíduo. No entanto, para Marcon, Andrade e Veneral (2014), para que as diretrizes da PNRS sejam obedecidas e as metas do Plano Nacional de Resíduos Sólidos sejam alcançadas, são necessários instrumentos e metodologias de sensibilização e mobilização capazes de influenciar os vários segmentos da sociedade, cabendo este papel à EA.

Criada para que as pessoas diminuam a produção de lixo, a política pedagógica dos 3 R's, trata-se de uma campanha para influenciar a população a poluir menos, minimizando os impactos negativos à natureza, por meio da redução do consumo dos recursos naturais, assim como o consumo consciente, reutilizando e/ou reciclando produtos e materiais utilizados no dia a dia. 


\section{METODOLOGIA}

\section{ÁREA DE ESTUDO}

O projeto foi realizado na Escola Municipal de Educação Básica (EMEB) Pe. Raimundo Pombo, localizada no bairro Parque Cuiabá, conforme coordenadas geográficas $56^{\circ} 02$ '27,00”W 1540’07,90”S, na cidade de Cuiabá/MT (Figura 1). A qual possui 10 salas de aula e atende a 478 alunos, da educação infantil (crianças de 4 e 5 anos) ao $5^{\circ}$ ano.

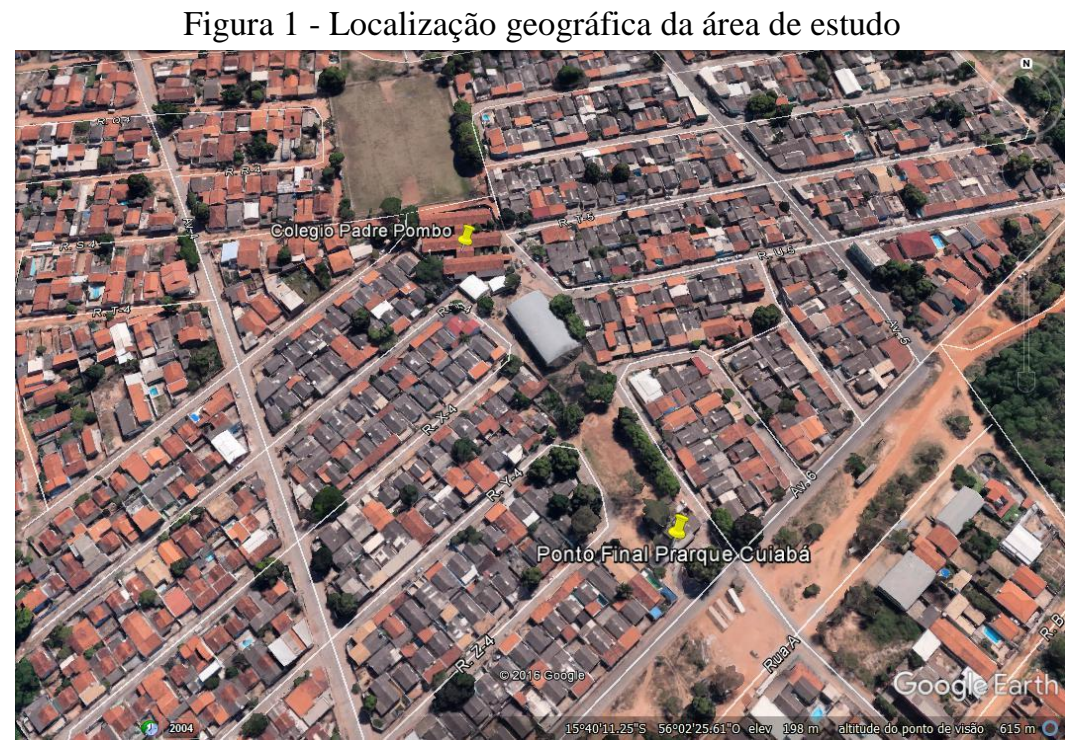

Fonte: Google Earth (2016).

\section{COLETA DE DADOS}

A metodologia empregada foi à qualitativa, que segundo Neves (2015) tem como principal objetivo interpretar o fenômeno em observação, consistindo em mostrar a realidade, e não abrir mão da observação, análise, descrição e compreensão dos casos a fim de entender seu significado.

O Projeto contou com a participação dos alunos do $5^{\circ}$ ano matutino, na faixa etária entre 09 e 12 anos de idade, assim como o apoio da professora regente para a realização das atividades. Foi executado nos meses de março e abril de 2017, onde foram coletados dados como: observação, depoimentos dos alunos, participações dos alunos em oficina de reciclagem e reutilização de materiais e registro fotográfico. 


\section{ATIVIDADES DESENVOLVIDAS}

Quadro 1 - Atividades desenvolvidas como metodologia na escola pública, em Cuiabá - MT

\begin{tabular}{|c|c|c|c|}
\hline Etapas & Atividades & Descrição & Obs: \\
\hline $1^{a}-29 / 03$ & Questionário & $\begin{array}{l}10 \text { Perguntas Percepção } \\
\text { Ambiental: } \\
\text { O que se entende sobre EA }\end{array}$ & $\begin{array}{l}\text { Aplicado Antes da Palestra Educativa. } \\
\text { A fim de identificar qual grau de } \\
\text { conhecimento dos alunos sobre o assunto. }\end{array}$ \\
\hline $2^{a}-29 / 03$ & Palestra & $\begin{array}{l}\text { Conceitos e Diferenciações: Lixo } \\
\text { e Resíduos Sólidos }\end{array}$ & $\begin{array}{l}\text { 1- Classificações de lixo; } \\
\text { 2- Locais corretos para a disposição final } \\
\text { dos resíduos sólidos; } \\
\text { 3- Problemas ambientais causados pela } \\
\text { disposição inadequada dos resíduos no solo, } \\
\text { na água e no ar; } \\
\text { 4- Política Pedagógica dos 3R }{ }^{\text {ce }} \text { (Reduzir, } \\
\text { Reutilizar e Reciclar); } \\
\text { 5- Benefícios da reciclagem. }\end{array}$ \\
\hline & Vídeo & Um Plano para Salvar o Planeta & Turma da Mônica \\
\hline \multirow[t]{2}{*}{$3^{a}-05 / 04$} & Oficina & $\begin{array}{l}\text { Reciclagem e Reutilização de } \\
\text { Materiais } \\
\text { Divididos em } 4 \text { Grupos }\end{array}$ & $\begin{array}{l}\text { Foram confeccionados diversos Brinquedos } \\
\text { Didáticos a partir dos materiais que eles } \\
\text { trouxeram de casa }\end{array}$ \\
\hline & Folder & Explicativo: 3R's & Com caça-palavras; Labirinto e Colorir \\
\hline $4^{a}-12 / 04$ & Questionários & $\begin{array}{l}1-\quad \text { Reaplicação do } 1^{\circ} \\
\text { Questionário } \\
2-\quad \text { Reciclagem e } \\
\text { Reutilização de Materiais } \\
\end{array}$ & $\begin{array}{l}\text { A fim de identificar se o conhecimento } \\
\text { aplicado foi absorvido pelos alunos. }\end{array}$ \\
\hline
\end{tabular}

Fonte: Próprio autor (2017).

\section{MATERIAIS UTILIZADOS}

Quadro 2 - Materiais utilizados para confecção dos brinquedos

\begin{tabular}{|l|l|l|}
\hline \multicolumn{1}{|c|}{ Brinquedo } & \multicolumn{1}{|c|}{ Material } & \multicolumn{1}{c|}{ Quantidade } \\
\hline \multirow{4}{*}{ Boliche } & Garrafa PET 500ml & 20 \\
\cline { 2 - 3 } & Tinta guache (amarelo, azul, verde e vermelho) & 1 pote 100ml de cada cor \\
\hline \multirow{5}{*}{ Jogo de Argolas } & Lata de batata chips & 18 \\
\cline { 2 - 3 } & Papéis de presente/laminado & Diversos \\
\cline { 2 - 3 } & Cola branca & 1 \\
\cline { 2 - 3 } & Tesoura sem ponta & 4 \\
\cline { 2 - 3 } & Caixa de papelão coberta com papel pardo & 2 \\
\cline { 2 - 3 } & Cola quente & 2 tubos \\
\cline { 2 - 3 } & Garrafa PET 2L (para as argolas) & 2 \\
\hline \multirow{5}{*}{ Jogo Resta 1 } & Papelão (40x40cm) coberto com papel pardo & 2 \\
\hline
\end{tabular}




\begin{tabular}{|l|l|l|}
\hline \multirow{5}{*}{ Jogo de Dama } & Canetão preto (para o desenho do tabuleiro) & 1 \\
\cline { 2 - 3 } & Tampas de garrafas PET & 64 \\
\cline { 2 - 3 } & EVA marrom (colocado em cima das tampinhas) & $1 / 2$ folha \\
\cline { 2 - 3 } & Tesoura sem ponta & 4 \\
\cline { 2 - 3 } & Cola para EVA & 1 \\
\hline \multirow{5}{*}{} & Papelão (40x40cm) coberto com papel pardo & 1 \\
\cline { 2 - 3 } & Canetão verde (para o desenho do tabuleiro) & 24 \\
\cline { 2 - 3 } & Tampas de garrafas PET & $1 / 2$ folha de cada cor \\
\cline { 2 - 3 } & EVA marrom e branco (colocado em cima das tampinhas) & 4 \\
\cline { 2 - 3 } & Tesoura sem ponta & 1 \\
\cline { 2 - 3 } & Cola para EVA & \\
\hline
\end{tabular}

Fonte: Próprio autor (2017).

\section{RESULTADOS}

O trabalho de Educação Ambiental foi aplicado para 22 alunos do $5^{\circ}$ ano Matutino, na faixa etária média de 10 anos, sendo $50 \%$ dos alunos do sexo feminino e $50 \%$ do sexo masculino. De modo geral, a turma tem um bom relacionamento interpessoal e apesar de ser um pouco agitada é participativa, interessada e possuem facilidade em organização e trabalho em grupo.

$\mathrm{Na} 1^{\text {a }}$ Etapa foi aplicado um questionário semiestruturado, Figura 2, com dez perguntas sobre percepção ambiental, de forma simples e de fácil entendimento, por se tratar de crianças, sendo 4 (quatro) perguntas somente de múltipla escolha; 3 (três) perguntas de múltipla escolha com pequeno comentário pessoal; e 3 (três) perguntas com resposta direta.

\section{Figura 2 - Aplicação do Questionário 1}

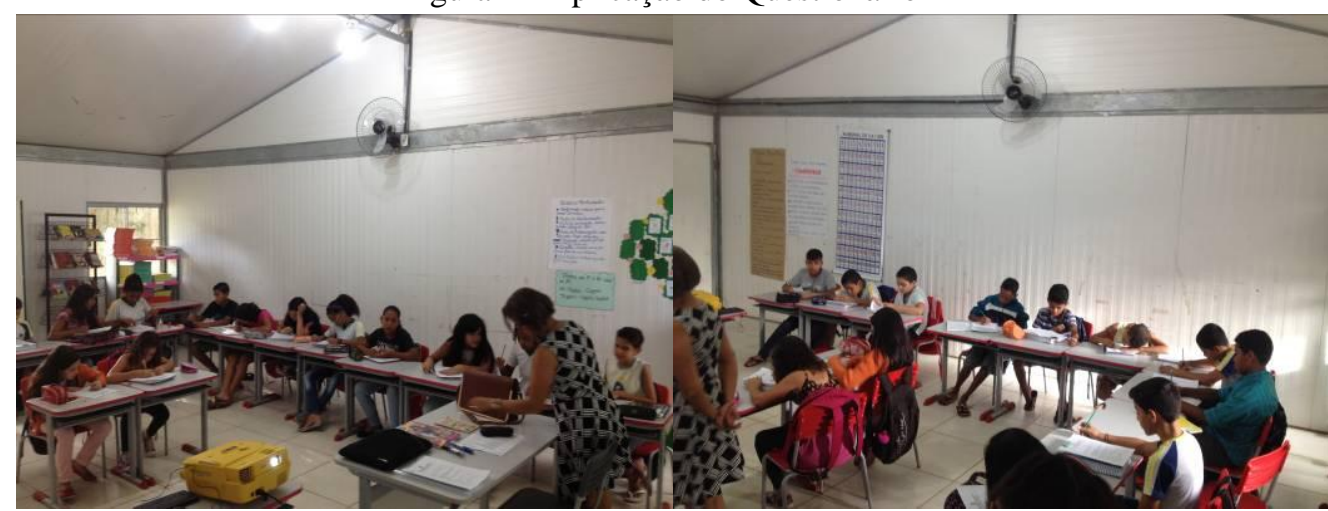

Fonte: Próprio autor (2017).

$\mathrm{Na} 2^{\mathrm{a}}$ Etapa, após palestra e vídeo, foi proposto aos alunos fazerem a separação dos resíduos sólidos em casa e trazerem tais materiais, Figura 04, que poderiam ser reutilizados para a fabricação de brinquedos didáticos na $3^{\text {a Etapa. }}$ 


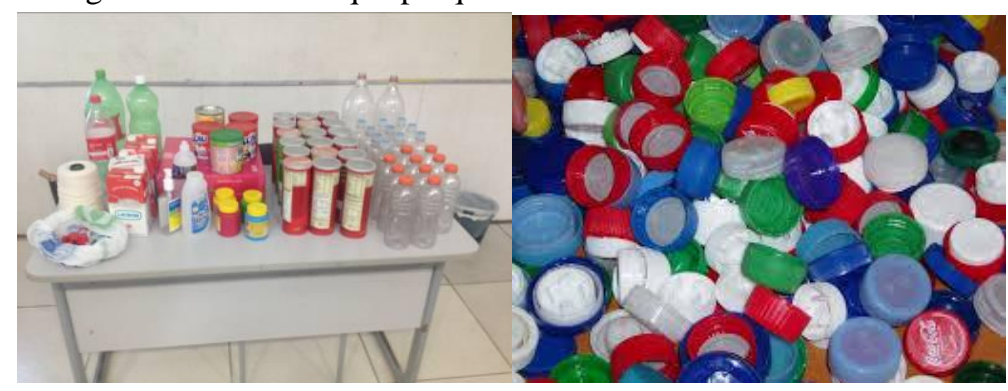

Fonte: Próprio autor (2017).

A turma foi dividida em 4 (quatro) grupos, para que pudessem transformar os resíduos sólidos em algo novo (brinquedos) para utilização durante o intervalo de aulas (recreio). A oficina resultou na confecção de 7 brinquedos mostrados na Figura 05, sendo: 2 (dois) Jogos de Boliche; 2 (dois) Jogos de Argolas; 2 (dois) Jogos Resta 1; e 1 (um) Jogo de Dama.

Figura 4 - Brinquedos confeccionados

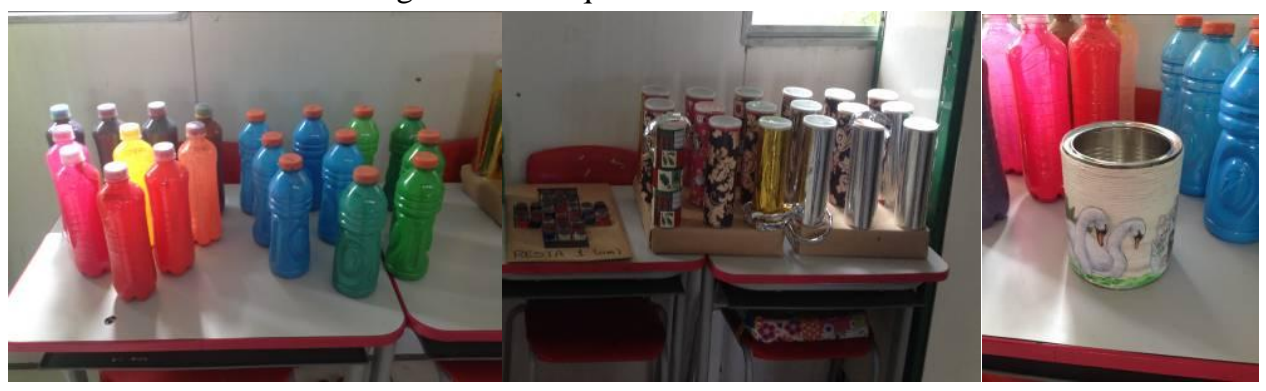

Fonte: Próprio autor (2017).

Após a oficina, os alunos limparam, separaram e guardaram os materiais que não foram utilizados durante a oficina, para criação de novos brinquedos em outra oportunidade, juntamente com a professora.

A $4^{\circ}$ Etapa foi realizada com o objetivo de identificar se os conhecimentos aplicados foram compreendidos pelos alunos, pois quando estão integrados neste meio são capazes de desenvolver este processo de transformação e promover a mudança.

\section{COMPARATIVO ENTRE A $1^{\text {a }}$ E $2^{\text {a }}$ APLICAÇÃo DO QUESTIONÁRIO SOBRE PERCEPÇÃo}

\section{AMBIENTAL}

A primeira aplicação do questionário foi feita antes da palestra educativa, o que influenciou na resposta para a segunda aplicação do questionário realizada duas semanas depois. Quando perguntado "Você já ouviu falar em Educação Ambiental?”, verificou-se um aumento de 8,29\% dos alunos cuja resposta foi 'sim' e a diminuição em 5,08\% dos alunos que responderam 'não', e houve um decréscimo de 3,21\% dos que não sabiam responder a questão. Quando a resposta foi 'SIM', foi perguntado 'Onde?', e 47,06\% responderam, na segunda 
aplicação, que já ouviram falar em EA na própria escola, no $4^{\circ}$ ano por meio do Projeto Mais Educação. Um aumento de $15,24 \%$ em relação a $1^{a}$ aplicação. Seguido de $17,65 \%$ que ouviram sobre EA no Horto Florestal, onde eles fizeram uma visita.

A segunda pergunta "Para você o que é meio ambiente?", foi de múltipla escolha com quatro opções de resposta. E nas duas aplicações, a grande maioria dos alunos responderam a opção mais adequada para a conceituação de meio ambiente "É o lugar onde vivem os seres vivos (plantas, animais e o homem) e os recursos (ar, água, solo e alimentos) que a natureza oferece". Observou-se que eles conseguiram compreender que o Meio Ambiente é tudo que está ao nosso entorno; a fauna, a flora, os ecossistemas e o local onde vivemos, portanto é dinâmico e oferece a inter-relação dos seres vivos com o meio ambiente.

Para a terceira questão "Você sabe a importância dos rios e das árvores para o planeta?", averiguou-se que houve uma mudança em todas as respostas. Ocorreu uma diminuição no percentual de alunos que não sabiam sobre a importância dos rios e árvores para o planeta e daqueles que não sabiam responder à questão. Portanto, aumentou também o número de alunos que compreendiam a importância desses elementos. Nessa questão, quando a resposta fosse sim, os alunos deveriam responder 'qual?', a resposta mais descrita por eles se referia a sobrevivência dos seres vivos, pois as árvores ajudam na respiração e a água na hidratação.

A pergunta 4 'De onde vem a água que chega a sua casa?', foi discurssiva, no entanto, algumas respostas foram semelhantes, sendo que na primeira aplicação: 63,64\% das respostas foram 'do rio'; $13,64 \%$ declararam que vinha da caixa d'água; $18,18 \%$ acreditam que vem da represa; e apenas 4,55\% respondeu que vem do rio, mas antes de chegar a sua casa passa por um tratamento. Já para a segunda aplicação, constatou-se uma diminuição dos alunos que consideram que a água que chega a sua casa vem dos rios e da caixa d'água, com 50\% e 4,55\%, respectivamente. Os que acreditam que a água vem de represas permaneceu 18,18\% e verificouse um aumento em $22,72 \%$ nos alunos que souberam responder que apesar da água vir do rio, antes dela chegar a nossa casa, passa por tratamento.

A questão 5 'O que acontece com a água depois que você a utiliza?', foi mal interpretada por $27,27 \%$ na primeira aplicação, onde responderam que utilizam no dia a dia para consumo. No entanto, $36,36 \%$ responderam que vai para o esgoto e desses, $12,5 \%$ disseram que recebem tratamento para então voltar ao rio. Na segunda aplicação esse índice mudou, sendo que 77,27\% responderam que a água vai para o esgoto e desses, $41,18 \%$ acreditam que o esgoto passa por tratamento antes de voltar ao rio. Isso indica que eles entenderam a proposta aplicada na palestra de que a poluição é toda alteração das propriedades naturais do meio ambiente e prejudicial à 
saúde, sendo que o esgoto quando tratado em uma Estação de Tratamento de Esgoto (ETE), retira todos os poluentes da água e assim poderá retornar para o rio.

Na pergunta “O que é solo para você?” foi possível verificar que os alunos sabem que o solo não é apenas o local de onde se obtêm areia e pedras, mas sim uma região de intensa atividade de microrganismos, composta por elementos minerais. Isso se mostrou evidente na segunda aplicação, onde diminuiu o percentual de alunos que acham que o solo é apenas o espaço de onde surgem as plantas, e zerando as outras duas alternativas, elevando assim, a 90,91\% dos alunos que marcaram a resposta mais adequada.

Foi perguntado 'Para que serve o ar?' na questão 7. E, na segunda aplicação do questionário, 40,91\% dos alunos mudaram de ideia, marcando a resposta mais coerente: 'Todas as respostas anteriores', visto que as demais opções eram: 'Para os seres vivos respirarem', 'Para se refrescar (Vento)', 'Para ajudar na reprodução de plantas', e 'Como fonte de produção de energia'.

Considerando a biodiversidade brasileira, foi elaborada a questão 8 "Qual das opções abaixo indicam animais da nossa região?”, em números absolutos, apenas um aluno se equivocou na resposta, marcando a opção 'canguru, tatu e papagaio'. Enquanto que os demais 95,45\% responderam a opção correta para os animais da região: 'jacaré, tuiuiu e garça'.

A Pergunta 9 'Para onde vai o lixo da sua casa?' Era caráter discursiva. Na primeira aplicação, 63,63\% dos alunos responderam que o lixo de sua casa vai para o lixão, desses, $14,29 \%$ disseram que no lixão são separados e levados para reciclagem. Os que disseram que o lixo da sua casa vai para reciclagem somam 27,27\% e 9,09\% disseram que o lixo vai para o esgoto. Durante a palestra foi demonstrado a Classificação de Resíduo; para onde ele vai depois de realizada a coleta pelo caminhão; locais corretos para a disposição final dos resíduos sólidos e os problemas ambientais causados pela poluição do solo, da água e do ar. Assim, eles entenderam melhor sobre a destinação do resíduo da sua residência, sendo que 90,91\% dos alunos responderam que o resíduo vai para o lixão, e desses, $40 \%$ acreditam que no lixão, os resíduos são separados e entregues para reciclagem.

Para a questão 10 'Você acredita que a poluição pode afetar a sua saúde?', na primeira aplicação, $100 \%$ dos alunos acreditavam que a poluição pode afetar a sua saúde, informando razões como: queimadas, acúmulo de lixo, poluição das águas e do ar. Enquanto que na segunda aplicação, 9,09\% marcaram a alternativa 'Não sei responder'. Quando a resposta foi ‘sim', foi perguntado 'Por quê?', e as respostas permaneceram as mesmas, nas duas aplicações: acúmulo de lixo, queimadas, poluição das águas e do ar. 


\section{APLICAÇÃO DO QUESTIONÁRIO SOBRE RECICLAGEM E REUTILIZAÇÃO DE MATERIAIS}

Considerando a proposta da palestra sobre demonstrar a diferenciação entre Lixo e Resíduo sólido, Política Pedagógica dos 3R's e Benefícios da Reciclagem e ainda, com a apresentação do vídeo "Um Plano para Salvar o Planeta" - Turma da Mônica foi elaborado um questionário com oito perguntas, das quais, seis eram discursivas e duas de múltipla escolha, sendo uma desta com pequeno comentário pessoal.

Para a Pergunta 1 'O que é reciclagem?' apenas 4,55\% não souberam responder a questão, enquanto que 95,45\% responderam, nas mais variadas descrições que reciclagem é transformar algo (resíduo) em outro produto. Alguns usaram como exemplo a oficina, realizada uma semana antes, onde utilizaram garrafas PET e tampinhas de garrafa para transformar em brinquedos.

A questão 2, "Qual a diferença entre lixo e resíduo", 40,91\% dos alunos acreditam que o 'lixo é reaproveitável e resíduo não', enquanto que 59,09\% marcaram a opção mais adequada 'lixo é o que não serve mais para o uso e foi descartado, e resíduo é o que não serve mais para você mas pode ser reaproveitado'. Isso mostra que houve uma pequena confusão dos alunos na relação lixo x resíduo.

Com a apresentação do vídeo Turma da Mônica em "Um Plano para Salvar o Planeta", realizada na segunda etapa do projeto e com a oficina sobre reciclagem e reutilização de materiais, na terceira etapa, onde foi entregue aos alunos um folder explicativo sobre a Prática dos 3R's, deram subsídios para que os alunos pudessem responder as questões 3 e 4.

Apenas 18,18\% dos alunos não souberam responder a questão 3 ' $O$ que significa Reduzir, Reutilizar e Reciclar?’ e 81,82\% responderam corretamente, com suas palavras, que: Reduzir é diminuir o consumo e produção do lixo em casa; Reutilizar é usar novamente uma embalagem; Reciclar é transformar um objeto em outro.

Em trabalho realizado em duas escolas com alunos do ensino fundamental, Silva (2014) relata que a grande maioria dos alunos responderam de maneira errada quando perguntados sobre os 3R's. Sendo que em uma das escolas teve a EA no ensino pedagógico e a outra não, no entanto, a diferença nas respostas não foram expressivas, demonstrando que a prática pedagógica não está sendo efetiva. $\mathrm{O}$ autor conclui que "é necessário investir no conhecimento do educador, pois ele é peça fundamental, essencial na formação do indivíduo" (SILVA, 2014 p. 27).

Quanto a questão 4 'Como posso aplicar a prática dos 3R's em casa?', 31,82\% não responderam ou declararam não saber respondê-la, enquanto que $68,18 \%$ responderam que 
pretendem reutilizar garrafas PET, latas de achocolatado etc., diminiuindo assim, a produção de lixo em casa. E quando os alunos responderam a Pergunta 5 'Qual a importância da reciclagem?' a grande maioria das resposta teve como base a preocupação com a poluição do meio ambiente, sendo algumas respostas: "a reciclagem é uma forma de não poluir o mundo"; "para ter um mundo melhor sem poluição"; "para diminuir a poluição"; "para o mundo ser melhor".

Na Pergunta 6 'O que você achou da oficina?', $100 \%$ dos alunos gostaram da oficina, a maioria respondeu apenas "legal" ou "muito bom", mas alguns justificaram melhor suas respostas como: "Legal, eu queria fazer de novo"; "Muito legal, eu aprendi muito, a experiência foi ótima"; "Bom porque a tia veio aqui e ensinou tudo sobre o lixo"; "Legal, vou fazer em casa um brinquedo que aprendi na oficina", sendo essa última, de uma aluna PNE.

Marins (2014, p. 26) em trabalho semelhante, concluiu que os brinquedos e jogos interativos proporcionam alegria e diversão às crianças e relatou o que um dos alunos achou da oficina: "o brinquedo é muito legal e sua construção não prejudica o meio ambiente, porque é feito com material que ia para o lixo". Isso demonstra a importância da aplicação da EA nas escolas desde o ensino básico, seja por meio de palestra ou realização de oficinas para confecção de brinquedos e jogos interativos, fazendo com que esses pequenos cidadãos entendam a importância da preservação ambiental, podendo levar esses conhecimentos para suas casas e vizinhanças, aprimorando o relacionamento do homem com a natureza.

Na pergunta 7 'Você acha importante a realização de oficinas sobre Reciclagem? Por que?', $13,63 \%$ não souberam responder, $4,55 \%$ acredita que não afeta em nada e $81,82 \%$ responderam que acham relevante a realização de oficinas sobre reciclagem, sendo que a maioria relacionou a importância de reciclar com a oficina que efetuamos na $3^{\mathrm{a}}$ etapa.

Os resultados da Pergunta 8 "Depois de ouvir a palestra e participar da oficina, você pretende praticar os 3R's na sua casa?", 18\% não souberam responder, $9 \%$ disseram que não pretendem praticar os 3R's em casa, e 73\% afirmaram que vão levar o que aprederam em sala de aula para sua casa, desenvolvendo hábitos melhores juntamente com seus familiares, dimnuindo a produção de lixo na sua residência. Quando a resposta foi 'SIM', os alunos deveriam responder 'Por que?' e a grande maioria acredita que é algo bom de se praticar e importante para o meio ambiente, por não poluí-lo.

Após pesquisa na literatura de trabalhos voltados a aplicação da Educação ambiental nas escolas, é possível observar que esta é uma ferramenta extremamente relevante e que deve ser trabalhada nas instituições de ensino desde a educação infantil, de forma dinâmica e 
participativa, a fim de proporcionar melhor entendimento e sensibilização dos alunos, levando esses conhecimentos para suas residências. O fato dos resultados obtidos na aplicação dos questionários terem diferença no percentual justifica-se por se tratar de alunos com dez anos de idade, e que os mesmos são agitados, portanto, preferem não responder ou mesmo marcar a opção não sei responder só para não ter que responder, de fato, as questões discursivas.

\section{CONSIDERAÇÃO FINAIS}

Por meio da realização da palestra, com orientações sobre reduzir, reutilizar e reciclar, além da aplicação de questionário, foi possível constatar claramente, que os alunos se mostraram sensíveis às questões ambientais e entenderam a importância de proteger o meio ambiente em que vivemos, não só para nossa sobrevivência, como para as futuras gerações.

A oficina sobre reciclagem e reutilização de materiais possibilitou avaliar e intervir, de modo a fazer com que o conhecimento fosse adquirido de maneira participativa e lúdica, ao contrário de apenas impor um conhecimento pré-estabelecido em sala de aula. Assim, foi possível proporcionar um aprendizado real e duradouro, muito mais significativo que um conteúdo decorado em sala.

A partir da proposta feita aos alunos para a separação dos resíduos sólidos em casa, assim como os resultados obtidos e o alto percentual de alunos que se mostraram interessados pelos assuntos voltados ao meio ambiente e a preocupação com a destinação final do resíduo, espera-se que estes levem a experiência que tiveram em sala de aula, para dentro de suas residências, influenciando nos hábitos familiares e até mesmo da vizinhança, disseminando assim os conhecimentos adquiridos

Conclui-se que as atividades desenvolvidas na EMEB, possibilitou o aumento da percepção como um todo, sobre o que os alunos entendem a respeito dos temas ligados ao meio ambiente, sua importância e a necessidade de proteção. Assim como tornarem-se cidadãos críticos com poder de decisão junto à sociedade, podendo contribuir na preservação ambiental, melhorando não só o ambiente ao seu redor como a comunidade onde estão inseridos.

\section{REFERÊNCIAS}

BONACORSO, Fabiano Moreira. Educação ambiental: Ensino x Aprendizagem. 2009. $62 \mathrm{f}$. Monografia (Especialista em Educação Ambiental) - Instituto a Vez do Mestre, Universidade Cândido Mendes, Florianópolis, 2009.

BRASIL. Constituição (1988). Constituição da República Federativa do Brasil. Brasília, DF: Senado 1988. 
BRASIL. Lei n. 9.795, de 27 de abril de 1999. Dispõe sobre a educação ambiental, institui a Política Nacional de Educação Ambiental e dá outras providências. Brasília, DF. Diário Oficial da União de 28 abr. 1999.

BRASIL. Lei n. 12.305, de 02 de agosto de 2010. Institui a Política Nacional de Resíduos Sólidos; altera a Lei n 9.605, de 12 de fevereiro de 1998; e dá outras providências. Brasília, DF. Diário Oficial da União de 03 ago. 2010.

DIAS, Genebaldo Freire. Educação Ambiental: princípios e práticas. 9.ed. São Paulo: Gaia, 2004.

LARANJA, Alyne Leite Brandão. Diagnóstico da percepção ambiental em uma escola pública no bairro Cohab Cristo Rei, em Várzea Grande-MT. 2016. 34f. Monografia (Tecnólogo em Gestão Ambiental) Instituto Federal de Educação, Ciência e Tecnologia de Mato Grosso. Cuiabá, 2016.

MARCON, Gabriele Teresa Gadens; ANDRADE, Márcia Cristina Kravetz; VENERAL, Débora Cristina. Os desafios da educação ambiental frente á política nacional de resíduos sólidos. Revista Meio Ambiente e Sustentabilidade, v. 5, n. 3, p. 119-137, jan/jun. 2014.

MARCZWSKI, Maurício. Avaliação da percepção ambiental em uma população de alunos do Ensino Fundamental de uma escola municipal rural: um estudo de caso. 2006. 188f. Dissertação (Mestrado em Ecologia) Pós-graduação em Ecologia, Universidade Federal do Rio Grande do Sul. Porto Alegre, 2006.

MARINS, Evandro dos Santos. Educação ambiental em uma escola municipal de Cuiabá (MT): Realização de atividades ambientais e análise dos seus impactos. 2014. 43f. (Tecnologia em Gestão Ambiental) Instituto Federal de Educação, Ciência e Tecnologia de Mato Grosso. Cuiabá, 2014.

MEDEIROS, Gleide Mirtes Batista de. A importância da Educação Ambiental como prática e vivência em uma escola estadual em Várzea Grande-MT. 2012. 37f. Monografia (Tecnologia em Gestão Ambiental) Instituto Federal de Educação, Ciência e Tecnologia de Mato Grosso. Cuiabá, 2012.

MEIRELLES, Maria de Souza; SANTOS, Marly Terezinha dos. Educação Ambiental: uma Construção Participativa. $2^{a}$ ed. São Paulo, 2005.

NEVES, Miranilde Oliveira. A importância da investigação qualitativa no processo de formação continuada em professores: subsídios ao exercício da docência. Revista Fundamentos, Piauí, v.02, n.1, p.17-31. 2015.

SANTOS, Elaine Teresinha Azevedo dos. Educação ambiental na escola: conscientização da necessidade de proteção da camada de ozônio. Santa Maria, 2007. 53f. Monografia (Pósgraduação em Educação Ambiental), Universidade Federal de Santa Maria, UFSM. 2007.

SILVA, Letícia Kédina da. Percepção ambiental dos alunos do ensino fundamental de duas instituições públicas de educação de Cuiabá/MT. Cuiabá, 2014. 31f. Monografia (Tecnologia em Gestão Ambiental), Instituto Federal de Educação, Ciência e Tecnologia de Mato Grosso, IFMT. 2014. 
SOUZA, Fernanda Silveira Carvalho de. Educação Ambiental: conferências. Cuiabá: Instituto Federal de Mato Grosso, 2014. 19f. Apostila.

Recebido em:04 de fevereiro de 2019.

Aprovado em: 02 de junho de 2019. 